\title{
Financial Situation Unique Indicator for Electric Sector Firms
}

\author{
Aracéli Cristina de S. Ferreira ${ }^{1}$, Vinicius Mothe Maia ${ }^{1}$, Dilo S. de Carvalho Vianna ${ }^{1}$ \& Juliana Molina Queiroz ${ }^{1,2,3}$ \\ ${ }^{1}$ School of Administration and Accounting, Federal University of Rio de Janeiro, Rio de Janeiro, Brazil \\ ${ }^{2}$ Multidisciplinary Institute, Rural Federal University of Rio de Janeiro, Nova Iguaçu, Brazil \\ ${ }^{3}$ Institute of Applied Social Sciences (ICSA), Federal University of Alfenas, Varginha, Brazil \\ Correspondence: Juliana Molina Queiroz, School of Administration and Accounting, Federal University of Rio de \\ Janeiro, Rio de Janeiro - RJ, Brazil.
}

Received: July 9, 2021

doi:10.5430/afr.v10n3p72
Accepted: August 20, 2021

Online Published: August 23, 2021

\begin{abstract}
This paper develops a unique indicator to identify the financial situation of firms in the electric sector in Brazil. The National Electric Energy Agency (ANEEL) regulates this sector through five dimensions: indebtedness, efficiency, investment, profitability, and pay-out ratio. Each of these dimensions contains one or two indicators. Based on these indicators, we develop a unique indicator that shows companies' financial situation. To create a unique indicator, we follow the idea of Altman's solvency indicator. But, we use a logit regression. Our dependent variable is Global Performance of Continuity which indicates the financial situation of the firm. Our independent variables are based on the five dimensions of the ANEEL indicators for financial situation. We collect data from 2011 to 2018. This research follows three main steps: (1) Collection of the data from the ANEEL database; (2) Creation of variables based on ANEEL's five dimensions of performance; and (3) Econometric proceedings with variables according to ANEEL's data and indicators of each dimension. First, we estimate one regression with all variables created based on ANEEL's five dimensions. Then, we make improvements to find a more suitable model with different combinations of variables. We chose the best model by analysing the Akaike information criterion (AIC). Our results show that the unique indicator we create to evaluate firm performance is based on Debt, Efficiency, Investment (CapexA) and the Pay-out Ratio.
\end{abstract}

Keywords: financial situation, electric sector, unique indicator, ANEEL

\section{Introduction}

The National Electric Energy Agency (ANEEL) of Brazil analyses the situation of firms by regulating their financial accounts. ANEEL is responsible for regulating the electric sector in Brazil and analyses firms based on their service performance compared to their financial performance. Recently, between 2011 and 2018, ANEEL developed some ways to regulate the financial situation of distributor, generator, and transmitter firms, particularly distributer firms. One way to regulate these firms is by analyzing their financial viability.

ANEEL analyses financial viability by supervising the electric sector using models or systematics of supervision that make up the dimensions of evaluation of financial viability (e.g., financial and operational). In 2016, ANEEL released the technical note "Nota Técnica 111/2016" (NT 111/2016), which presents the new regulation modeling. NT shows different dimensions of performance indicators.

In February 2019, the British Columbia Hydro and Power Authority and the British Columbia Utilities Commission discussed, among other issues, the opportunities and challenges associated with the adoption of performance-based regulation (PBR) (Lowry and Makos, 2020), indicating the need to review regulatory models to focus on performance analysis. Over the years, this dynamic has led to new questions about regulatory models and their performance indicators. Thus, the need for complementary work remains active. Along the same lines of thought, Braga, Rufin, Brandão, and Torres (2016) point out the need for the study and development of regulatory models by indicating that "the financial supervision of electricity distribution companies is still in an initial stage in academic centers, government agencies, and international regulators."

This paper is relevant because it is important to analyze how the regulatory agencies evaluate the electric sectors. Thus, the objective of this paper is to develop a unique indicator of energy company performance based on the National Electric Energy Agency's indicators. 
We develop a methodology based on multiple regressions. We analyze electric distributor firms from 2011 to 2018 and analyze different models based on ANEEL's indicators to pursue the "ideal" model, which may be able to show the firm's performance more quickly.

The challenge of implementing the single indicator is to be able to condense a complex reality and a single variable from the point of view of Altman's indicator. The lack of a historical series with companies that survived and failed is a limitation (because it is a market regulated where companies are sold or merge to survive) and thus applied the same model developed by him.

The idea of the single indicator would be to condense the company's situation into a single index. In this sense, we use the idea employed by Altman (1968) in his insolvency indicator as a starting point. Altman (1968) develops a unique indicator for bankruptcy by proceeding with discriminant analysis. In this paper, we develop a unique indicator by using a logit regression and its betas and signs of the coefficients of the variables included in the "ideal" model.

This paper is highly relevant because both ANEEL and the energy sector in Brazil would benefit from creating this unique indicator, which would facilitate the control and the scope of the expected performance of these firms. Currently, ANEEL uses a list of indicators and evaluates these firms quantitatively and qualitatively based on the sector's regulatory agency. Additionally, ANEEL evaluates the performance of each electric institution in each of these indicators.

Because there are many indicators, distributors take much time to analyze if they have achieved the expected results, often obtaining good performance in some indicators and poor performance in others, without having a clear definition of their situation. On the other hand, with the unique indicator, ANEEL and these firms may accelerate the process of analyzing and evaluating performance in general. Thus, this paper shows how we can analyze ANEEL indicators by testing a unique indicator. The results may help both electric firms and ANEEL to analyze the performance by applying this unique indicator.

We provide analyzes in this paper that can be replicated to those firms in the electrtic sector in Brazil along a different period. In the same way, it is possible to reproduce similar analyzes in other regulated sector in Brazil or in other country which also uses different indicators to analyze performance. In other words, this paper provide a way to develop a unique indicator to analyze performance for those cases.

\section{Literature Review}

\subsection{Monitoring Firm Performance in Regulated Sectors}

In finance, research regarding regulation has grown into a debate and study of the challenges of financial supervision and economic-financial perspective alternatives from several different sectors around the world (Borio, 2003; Solver, 2005; Wymeersch, 2007; Treasury, 2009; Čihak e Podpiera, 2009; Pan, 2010; Hilbers, Raaijmakers; Hu, Yin e Zheng, 2016; Ringe, Morais \& Ramos Munoz, 2019; Lowry e Makos, 2020).

Borio (2003) argues that it is desirable to strengthen the current prudential framework's macroprudential orientation to improve the safeguards against financial instability. The paper also compares macro- and microprudential dimensions and shows that financial regulatory and supervisory arrangements inevitably coexist. Financial instability is examined, and the conclusions of this coexistence and the desirability of policy efforts are shown. In this way, the necessity of regulation is notorious.

The energy sector is regulated by governmental institutions in many countries around the world. The regulations' main objective is to identify the financial viability of electric firms, which requires the analysis of firm performance. Over the years, many studies regarding the analysis of the monitoring method of electric sector performance have been carried out. The main papers regarding the analysis of the developed systematics and models adopted by the financial supervision of the electric sector are those of Ergas e Small (2001), Arocena e Price (2002), Mehdi et al. (2007), Jamasb e Pollitt (2008), Braga et al. (2016), and Huenteler et al. (2017). These studies analyze performance methods' evaluation, efficiency benchmarking, price cap, and return rates, which means that these papers generally analyze the way that the electric sector has been regulated. All these studies have something in common; they all indicate that energy company performance is due to the regulatory models. In other words, the regulation guides the performance of electric firms.

Generally, the performance models regulate the electric sector based on different dimensions, including the financial dimension. Performance indicators evaluate the financial dimension. Over the years, a line of research has emerged in which many papers have studied the challenges and alternatives of financial supervision in the electric sector, 
including Ergas and Small (2001), Pombo (2001), Arocena and Price (2002), Mehdi, Fetz and Filipini, (2007), Ribeiro, Macedo and Marques (2012), Braga et al. (2016), Huenteler et al. (2017). These studies show the systematics and models adopted to carry out financial supervision of the electric sector.

\subsection{Monitoring Firm Performance in the Electric Sector}

Meenakumari and Kamaraj (2008), Tallapragada et al. (2009), and Kishore and Varun Kumar (2018) analyze the performance indicators of electric sector institutions around the world. In 2019, the British Columbia Hydro and Power Authority and the British Columbia Utilities Commission discussed the opportunities and challenges associated with the adoption of regulations based on performance. They indicate the necessity of reviewing regulatory models to focus on performance analysis (Lowry and Makos, 2020).

Meenakumari and Kamaraj (2008) analyze the measurement of the relative efficiency of state electric utilities in India. This paper uses different DEA models to evaluate the relative efficiency of these firms. According to the authors, the results and discussions of this paper can be used to assist authorities in paving the way for improvements in technical and scale efficiency.

Tallapragada et al. (2009) also analyze the performance of firms in the electric sector to provide information regarding the impact of the reform on the electricity sector in Sub-Saharan Africa's firm performance. To analyze this impact, the paper develops a performance benchmarking approach considering the electric utility capacity assistance program (EUCAP) created by the World Bank. To proceed with the benchmarking analysis, it is necessary to select some key performance indices, which the paper used to reflect major elements of day-to-day utility operations. The paper develops a framework to compare the performance of firms in the electric sector using these indicators.

Finally, Kishore and Varun Kumar (2018) also analyze the performance of firms in the electric sector. This paper proposes a methodology to assess and optimize operational and financial performance using a multivariable techno-commercial performance evaluation. According to the authors, this paper is the first to empirically address the question of firm performance in the electric sector. They use absolute values of the parameters defined in the integrated rating methodology.

Huenteler et al. (2017) indicate the lack of studies regarding regulatory models and suggest that there is a limitation in the research regarding institutional determinants and the prerequisites for cost recovery and financial viability. The authors also argue that these studies should be rigorous, which is why some studies have developed over time to become increasingly empirical and pragmatic (Huenteler et al., 2017).

\subsection{Monitoring Firm Performance in Regulated Sectors in Brazil}

In Brazil, research on monitoring performance began with the 2006 study by Bezzerra and Corrar (2006). Since then, other papers regarding the analysis of financial supervision through performance indicators in regulated markets (insurance, health insurance, educational institutions, energy distribution, and banking institutions) have been published in Brazil (Bezerra and Corrar, 2006; Soares, 2006; Breitenbach, Alves and Diehl, 2010; Mendonça, Souza and Campos, 2016).

Bezerra and Corrar (2006) identify the use of financial indicators to assess the performance of firms in the financial sector. The analysis uses some indicators that, according to the authors, are used to compare firms or to compare different units of the same company. This paper uses a factor analysis to propose a methodology that decreases the subjectivity of the choice of indicators that are used to evaluate the companies. Additionally, this methodology allows the simultaneous analysis of the behavior of various indicators.

Breitenbach, Alves and Diehl (2010) aim to develop a set of financial performance indicators that are calculated, analyzed, and evaluated by general managers of educational institutions. The paper uses a benchmarking that allows for self-assessment and indicates the need for strategic changes. The paper first conducts a literature review regarding accounting analysis. According to the authors, after first calculating the indicators, it was possible to systematize a set of indicators. Based on these indicators, schools are able to improve financial performance.

Finally, Mendonça, Souza and Campos (2016) also aim to analyze the performance of financial institutions. In this paper, data envelopment analysis (DEA) is applied to a set of economic and financial indicators. The indicators analyzed by the authors are two input variables, and two output variables: the efficiency ratio and the operating cost index; and the return median of credit operations and the return on equity, respectively. The results of this paper show that two banks have achieved maximum efficiency in each year of the analysis. Additionally, the paper identifies that the efficiency ratio and return on equity are problematic indexes to evaluate firm performance.

In this paper, we analyze the ANEEL indicators according to NT n. 111/2016 of ANEEL. ANEEL analyses seven 
different indicators to evaluate the financial situation of firms in the electric sector. We explain the seven incators used by ANEEL in the Research Methodology. In this paper, we develop a unique indicator using these seven indicators based on Altman's (1968) idea.

Altman (1968) indicates that the research was moving toward eliminating ratio analysis as an analytical technique to measure firm performance. Investigating a set of financial and economic ratios related to bankruptcy, it was possible to analyze multiple discriminants to develop a unique indicator to assess a prediction of the bankruptcy of each firm.

\section{Research Methodology}

This research is carried out in three main steps: (1) Collection of the data in the ANEEL database https://www.aneel.gov.br/dados/relatorios; (2) Creation of variables based on ANEEL's five dimensions of performance and corresponding indicators; and (3) Econometric proceedings with variables according to ANEEL's data and indicators of each dimension.

We collect the data from ANEEL's website, which publishes data from the electric sector annually. We gather data from 2011 to 2018. We use this period because, in addition to the technical note "Nota Técnica n. 111" that has been available since 2016, we use data from the entire historical archive that ANEEL provides while we write this paper.

We create the variables based on the ANEEL database and according to Table 1, which shows ANEEL's indicators for the five dimensions: Indebtedness, Efficiency, Investments, Profitability, and the Pay-out Ratio.

Table 1. Description of the performance indicators (dependent variable)

\begin{tabular}{|c|c|c|}
\hline Dimension & Variable & Description \\
\hline Indebtedness & Debt & $\begin{array}{l}\text { Net Debt with Sectorial Financial Assets and Liabilities/(Adjusted } \\
\text { Earnings Before Interest, Taxes, Depreciation and Amortization } \\
\text { (EBITDA) - Regulatory Reintegration Quota) }\end{array}$ \\
\hline \multirow[t]{2}{*}{ Efficiency } & Efficiency 1 & $\begin{array}{l}\text { Adjusted Earnings Before Interest, Taxes, Depreciation and } \\
\text { Amortization (EBITDA)/ }\end{array}$ \\
\hline & Efficiency 2 & (Adjusted PMSO UDM/Regulatory PMSO UDM)/-1 \\
\hline Investments & Investments & $($ Capex U4/5A)/-1 \\
\hline \multirow[t]{2}{*}{ Profitability } & Profitability 1 & (Adjusted EBIT UDM - Regulatory EBIT)/(BRL + Incremental) \\
\hline & Profitability 2 & Sectorial Constitution/Regulatory EBIT UDM \\
\hline Pay-out Ratio & Pay-out Ratio & Shareholder Flow UDM/Liquid Earnings UDM \\
\hline
\end{tabular}

Discription: Indicators from ANEEL's technical note "Nota Técnica 111" of 2016.

Table 1 shows that the ANEEL analysis is five dimensions: Indebtedness, Efficiency, Investments, Profitability and the Pay-out Ratio. Efficiency and profitability are analyzed using two different indicators: Efficiency 1 and Efficiency 2; and Profitability 1 and Profitability 2.

We also create the dependent variable Global Performance of Continuity (GPC), which is an indicator of continuity of the service according to ANEEL. We present its description in Table 2.

Table 2. Description of the Global Performance of Continuity indicator (dependent variable)

\begin{tabular}{|c|c|c|}
\hline Indicator & Variable & Description \\
\hline Global Performance of Continuity & GPC & $\begin{array}{l}\text { According to the Duration of the Equivalent } \\
\text { Interruption per Consumer Unit (DEC) and Frequency } \\
\text { of Equivalent Interruption per Consumer Unit (FEC). } \\
\text { Dummy variable for Continuity, in which the firm } \\
\text { receives } 1 \text { if it shows GPC above the median and } 0 \text { if } \\
\text { it shows GPC below the median. }\end{array}$ \\
\hline
\end{tabular}

Discription: Indicators created by authors.

Table 2 presents the description of the GPC, which is based on the ANEEL report "Electricity Distribution Procedures in the National Electric System - Module 8 for Electric Power Quality." According to ANEEL, this indicator is known as the "continuity ranking". The GPC aims to compare the performance of a distributor concerning other companies in the country. In this way, we measure the GPC in the same way ANEEL analyses it. 
The GPC is based on two different indicators: Duration of the Equivalent Interruption per Consumer Unit (DEC) and Frequency of Equivalent Interruption per Consumer Unit (FEC). The DEC and FEC are indicators calculated by the distributors and sent periodically to ANEEL to verify the continuity of the service provided, representing, respectively, the time and the number of times that a consumer unit was without electricity for the period considered (month, quarter, or year), which allows the agency to assess the continuity of the energy offered to the population.

According to ANEEL, the indicator allows assessing the level of continuity of the distributor's service (values determined for duration and frequency of interruptions) concerning the limits established for its concession area (limits determined by ANEEL's authoritative resolutions).

Additionally, we create a dummy variable for the GPC to use as a dependent variable in a logit regression. We use the median of quality (GPC) to define the initial cut of the first estimation of the model, dividing the companies annually into two groups of the same size, where $50 \%$ of companies with the best quality received 1 and the others received 0 .

Finally, we create control variables, which we present in Table 3.

Table 3. Description of the control variables (independent variable)

\begin{tabular}{ccl}
\hline Indicator & Variable & \multicolumn{1}{c}{ Description } \\
\hline Equity Composition & EC & $\begin{array}{l}\text { Dummy variable for Equity Composition in which } \\
\text { the firm receives 1 if it is a governmental firm, and 0 } \\
\text { otherwise. }\end{array}$ \\
Size & Size & $\begin{array}{l}\text { Dummy variable for Size in which the firm receives 1 } \\
\text { if it has more than 400,000 consumers, and 0 } \\
\text { otherwise. }\end{array}$ \\
\hline
\end{tabular}

Discription: Indicators created by authors.

As shown in Table 3, we create two different control variables based on the equity composition and size using the ANEEL analysis. The ANEEL analysis considers these characteristics when evaluating the performance and continuity of firms. The first control variable is based on equity composition, in which the firm receives 1 if it is a governmental firm, and 0 otherwise. These two controls were implemented in different ways.

The difference between public and private companies would lead public companies to have greater inefficiency than private ones. Braga et al. (2016) shows that Equity Composition may lead to different forms of risk recognition and management. Thus, performance indicator may vary according to firms Equity Composition (governmental and non-governmental firms). For that reason, public firms would go out of their way, but it would not change the relationship between ANEEL's indicators and the impact on the distributor. So, this variable would only enter in the additive form to control possible effects of Equity Composition.

On the other hand, the use of an indicator Size is due to the difference between small and large distributors, suggesting a difference in the company's relationship and the indicator. ANEEL uses the cut of 400,000 consumers. If the company has more than 400,000 consumers, ANEEL consideres it large, otherwise it is considered small. Additionally, the analysis of Size is important because larger firms may show an advantage due to size in and of itself. Due to this fact, we analyze that variable alone or we include the interactions between these control variables with ANEEL's indicators by multiplying each of the ANEEL indicators and the dummy variables of control in the regressions.

We decide to create a unique indicator by using a logit regression, which means that the dependent variable is binary (zero, 0 , or one, 1). Our dependent variable is GPC, and our independent variables are based on the five dimensions of the ANEEL indicators.

We first estimate the logit regression as follows:

$$
y=\beta_{0}+\beta_{1} X_{1}+\beta_{2} X_{2}+\cdots+\beta_{n} X_{n}
$$

From this first estimation, we try to make improvements to find a more suitable model. The adequacy of the model was given by the Akaike information criterion (AIC), which indicates that a model with a lower value would be preferable. After that, we proceed with the following steps:

1- Companies with a score calculated by the model close to $0.5([0.45 ; 0.55])$ were identified, and their classification values ( 0 or 1 ) were changed from 0 to 1 and from 1 to 0 - 
2- The model was then reestimated with these changes made to the initial classification.

3- If the model had a better AIC, this new classification would become the base classification, and this process would be restarted until it was no longer possible to reduce the AIC index.

Figure 1 shows how we proceed with these estimations.

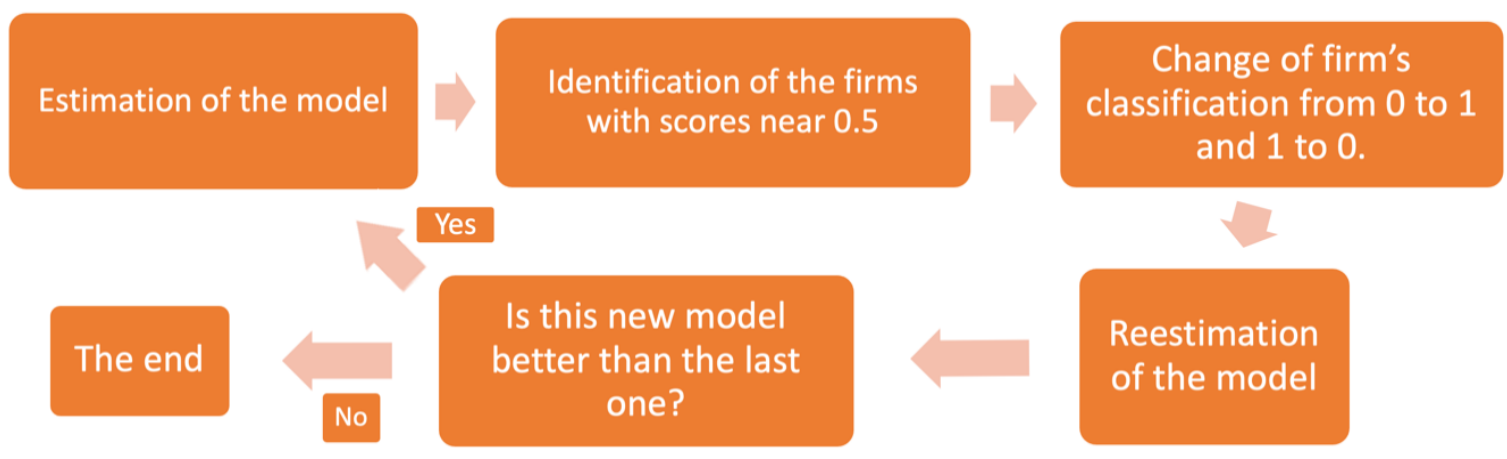

Figure 1. Proceedings to find better logit regression

Once we obtained the ideal model, we analyzed the independent variables employed. More specifically, we analyze the betas of each of the variables evaluated to see if there would be support, in theory, for the obtained signal. In this way, several models were tested based on the five dimensions of ANEEL indicators.

An example of what the model would look like is:

$$
y=\beta_{0}+\beta_{1} D_{e b t_{i t}}+\cdots+\beta_{n} \text { Size }+E C_{i t}+\varepsilon_{i t}
$$

We analyze the signal of each variable according to ANEEL's expectations. Table 4 presents the expected signs of these variables.

Table 4. Expected signs of each variable

\begin{tabular}{|c|c|}
\hline Variable & Expected Sign \\
\hline Debt & Negative (-) \\
\hline Efficiency 1 & Positive (+) \\
\hline Efficiency 2 & Negative (-) \\
\hline Investments & Positive (+) \\
\hline Profitability 1 & Positive (+) \\
\hline Profitability 2 & Positive (+) \\
\hline Pay-out Ratio & Positive (+) \\
\hline Equity Composition & Negative (-) \\
\hline Size & Positive (+) \\
\hline
\end{tabular}

Discription: Created by authors.

ANEEL makes it clear that it wants companies to be economically sustainable. Nevertheless, it is not useful if firms are profitable for shareholders if they offer poor and inefficient services. Ultimately, ANEEL seems to want good service and then "happy companies", which seems reasonable from the regulatory agency's point of view.

Before implementing the unique indicator test, we calculate and show the descriptive statistics and correlation of the variables, the level of missing data, and the possible existence of multicollinearity between the variables.

Because of this initial assessment, we decide to estimate the models with the original data and the winsorized data at $2.5 \%$. Thus, we tried to assess whether extreme values would cause problems in the models. As the results for the analysis of outliers did not make any difference, they were kept with the original data for simplicity.

Finally, to complete and confirm our results, we provide the results of our idea of the unique indicator to the 
Brazilian Association of Electric Energy Sector Accountants - ABRACONEE and to ANEEL, so that they could evaluate our model. They judged the model's accuracy in terms of classifying the companies among themselves. We send them a list with the value of the unique indicator of each firm for them to analyze our model. At the end of this process, we have a percentage of correct indicators of firms as "good" or "bad."

\section{Results}

The objective of this paper is to develop a unique indicator to analyze firm performance in the electric sector. In gathering data from the database through ANEEL's website, we found that some relevant information was missing. Then, we proceeded with descriptive statistics to analyze which variables could be included in our analyses and which ones should be eliminated.

Table 5 presents the descriptive statistics of each variable used in our tests.

Table 5. Descriptive Statistics of each variable

\begin{tabular}{lccccccc}
\hline & Debt & Efficiency 1 & Efficiency 2 & Investment & Profitability 1 & Profitability 2 & Pay Out Ratio \\
\hline N. Observ. & 520 & 520 & 520 & 520 & 520 & 520 & 520 \\
Missing Obs. & 24 & 17 & 24 & 217 & 77 & 457 & 73 \\
Min. & $-286,77$ & $-5,39$ & $-1,24$ & $-0,30$ & $-9,42$ & $-53,01$ & $-9609,51$ \\
Max. & 395,00 & 5,60 & 10,67 & 14,81 & 1,03 & 34,47 & 827,23 \\
First Quartile & $-0,18$ & 0,20 & 0,15 & 0,63 & $-0,08$ & $-0,20$ & 0,00 \\
Third Quartile & 6,20 & 0,53 & 0,60 & 1,82 & 0,06 & 0,16 & 1,07 \\
Mean & 3,41 & 0,28 & 0,59 & 1,64 & $-0,10$ & $-0,16$ & $-20,86$ \\
Median & 2,89 & 0,40 & 0,36 & 1,06 & 0,00 & 0,00 & 0,02 \\
Stand.Dev. & 30,44 & 0,60 & 1,13 & 2,07 & 0,64 & 9,17 & 465,10 \\
Asymmetry & 2,71 & $-1,99$ & 5,18 & 3,98 & $-10,22$ & $-1,63$ & $-19,62$ \\
Kustosis & 78,27 & 32,24 & 33,31 & 19,38 & 125,58 & 19,87 & 401,25 \\
\hline
\end{tabular}

Discription: ANEEL's data from 2011 to 2018 (ANEEL`s website).

According to Table 5, Profitability 2 shows 457 missing values, and consequently, we decide to cut this variable. Investment also shows a relevant number of missing values. Consequently, we continued trying to determine whether this variable would create some bias in our results along with the tests of our models. The missing values of the variable Investments are due to the fact the Investments is associated with CAPEX for five years depending on the tariff review.

It is important to remember that some public and official data from ANEEL seem to indicate some problems. For example, some indicators present results without any logic, such as investments with negative signs and very extreme values.

Table 6 shows the correlations between variables according to Pearson and Spearman tests.

Table 6. Pearson and Spearman correlation

\begin{tabular}{lccccccc}
\hline & Debt & Efficiency 1 & Efficiency 2 & Investment & Profitability 1 & Profitability 2 & Pay Out Ratio \\
\hline Debt & & 0,044 & $-0,062$ & 0,003 & 0,031 & $-0,014$ & 0,005 \\
Efficiency 1 & $0,175^{* * *}$ & & $-0,550^{* * *}$ & $-0,227 * * *$ & $0,593^{* * *}$ & 0,006 & 0,011 \\
Efficiency 2 & $-0,084^{*}$ & $-0,490^{* * *}$ & & $0,196 * * *$ & $-0,576^{* * *}$ & 0,008 & 0,010 \\
Investments & 0,012 & 0,016 & $-0,159 * * *$ & & $-0,505^{* * * *}$ & $-0,112$ & 0,037 \\
Profitability 1 & $0,181^{* * *}$ & $0,437 * * *$ & $-0,397 * * *$ & $-0,026$ & & $-0,112$ & $-0,001$ \\
Profitability 2 & 0,026 & $-0,104$ & 0,024 & $-0,372 * * *$ & 0,162 & & $0,738^{* * *}$ \\
Pay Out Ratio & $-0,012$ & $0,150^{* * *}$ & $-0,203^{* * *}$ & 0,029 & $0,161 * * *$ & 0,184 & \\
\hline
\end{tabular}

Note: Person's correlation is presented above the diagonal and Spearman's correlation is presented below the diagonal. Significance * $10 \%, * * 5 \%$ e ***1\%. 
Table 6 shows the correlation between variables and, consequently, presents some supposed problem of multicollinearity among the variables. We decide to analyze the correlations between variables because they may cause some problems in our tests. In this way, we judge the necessity to cut some variables because of possible eventual multicollinearity. Multicollinearity may be because some variables also contain information from other variables. According to Table 6, the variable Efficiency 1 shows a fair correlation with Efficiency 2, which means that we analyze these variables in different models. Additionally, Profitability 2 shows a high correlation with the other variables, such as Efficiency 1 and the Pay-out Ratio.

After analyzing the descriptive statistics of these variables, we tested many different models to funnel them into a small number of more suitable models in search of the "ideal" model.

The first model we estimate contains the following indicators of ANEEL: Debt, Efficiency 1, Efficiency 2, Investments, Profitability 1 and Pay-out Ratio. We estimate the models with and without controls of Size and the dummy variable for private and public firms. Additionally, we estimate these models with original and winsorized data.

In all of the tests, the results show "good" results according to our methodology: the coefficients of the variables did not make much sense according to the signs and significances. For instance, the Investment variable investment shows a negative beta, both Efficiency indicators have positive betas, Profitability with a negative beta, etc. The winsorization of the data also did not seem to have any effect.

Based on these results, we decided to analyze the dimensions of ANEEL, and we conclude that we could reduce these indicators. In that way, we drop Efficiency 2 because it has shown a high correlation with Efficiency 1 . In the same way, we decide to continue with Efficiency 1 and drop Profitability 1 because both Profitability 1 and Efficiency 1 are indicators that contain information from the operational earnings of the firms, which means that they capture the same information (we also analyzed the correlation between them). Additionally, the variable Investment did not seem to add up, so we chose to replace it with an annual measure, as opposed to a measure that added four or five years to one measure only. In this case, the variable Investment was replaced by CapexA, which is measured as follows:

$$
\text { Capex }=\text { Capex } / \text { Ativo }
$$

Finally, we continue our analyses with the following variables: Debt, Efficiency 1, CapexA and Pay-out Ratio. We estimate the models with the original and winsorized variables, as well as with and without the dummy variables for Size and Private and Public firms.

The winsorization did not substantially alter the results. Additionally, the controls seem to have once again not contributed. At the end of the model, only with these variables did we obtain a result that was as expected.

According to our methodology of analyzing signs and betas themselves, we finally achieved our "ideal" model, which is:

$$
y=\beta_{1}+\beta_{2} \text { Debt }+\beta_{3} \text { Efficiency } 1+\beta_{4} \text { CapexA }+\beta_{5} \text { PayOutRatio }
$$

Table 7 shows the results of the "ideal" model based on Debt, Efficiency, Capex A and the Pay-out Ratio.

\begin{tabular}{|c|c|c|c|c|}
\hline \multicolumn{5}{|c|}{$y=\beta_{1}+\beta_{2}$ Debt $+\beta_{3}$ Efficiency $1+\beta_{4}$ CapexA $+\beta_{5}$ PayOutRatio } \\
\hline & Coefficient & Standard-error & Stats. Z & P-value \\
\hline Intercept & $-0,4803$ & 0,2493 & $-1,9270$ & $0,0540 *$ \\
\hline Debt & $-0,0193$ & 0,0079 & $-2,4570$ & $0,0140 * *$ \\
\hline Efficiency 1 & 0,7177 & 0,3427 & 2,0950 & $0,0362 * *$ \\
\hline CapexA & 4,8754 & 2,2863 & 2,1320 & $0,0330 * *$ \\
\hline PayOutRatio & $-0,0012$ & 0,0013 & $-0,9230$ & 0,3561 \\
\hline
\end{tabular}

Table 7. Results of the "ideal" model

Discription: Significance $* 10 \%, * * 5 \%$ e $* * * 1 \%$.

Table 7 shows the results in line with our expectations. Only the Pay-out Ratio does not show a significant beta. However, the results presented in Table 7 show I beta signals according to what we and ANEEL were expecting. 
Almost all of the variables show significant betas. The model is also thrifty, as we expected.

The regression results now allow us to create a single indicator from the results found. We summarize the idea of the single indicator, as it is the final objective of the work. We calculate the unique indicator for each company from the previous results as follows:

UniqInd $=-0,480-0.019 *$ Debt $+0,718 *$ Efficiency $1+4,875 *$ CapexA $-0,001 *$ PayOutRatio

We follow with the unique indicator in a scale that goes from positive infinite to negative infinite. We do not convert the results, as would be expected in a logit regression for the function of the probability, which would show values

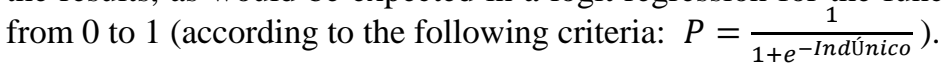

Our decision is justified because we prefer a scale where zero is the neutral value, as it is believed that it would facilitate decision making by managers since they would prefer positive values on this scale and be averse to negative values.

Based on our knowledge of the sector, we create analysis zones which are explained in Figure 2, following Altman's idea.

\begin{tabular}{|c|c|c|c|}
\hline \multicolumn{4}{|c|}{ Analysis Zones } \\
\hline$-1>X$ & $-1<X<-0.5$ & $-0.5<$ or $=X<$ or $=0.5$ & $X>0.5$ \\
\hline \multicolumn{4}{|c|}{ Description of the colors/zones } \\
\hline & \multicolumn{3}{|c|}{ The firm is not in a good situation } \\
\hline & \multicolumn{3}{|c|}{ The firm does not seem to be in a good situation } \\
\hline & \multicolumn{3}{|c|}{ The firm is not in a bad situation } \\
\hline & \multicolumn{3}{|c|}{ The firm is in a good situation } \\
\hline
\end{tabular}

Figure 2. Analysis Zones of the Results regarding the Unique Indicator

Finally, we proceeded with a practice test, as a validation of our results. We sent the results of the firms to many different agents in the electric sector, such as agents from ANEEL and the distributor firms themselves. In this way, they are able to analyze our unique indicator and to judge how well our assigned indicator value reflected the reality of the company.

The answer is that they fully agree with the results presented by our unique indicator. Thus, ANEEL agree that our unique indicator reflects the performance of the companies in the sample. Additionally, they agreed that they are willing to use the unique indicator to analyze firm performance. The justification to use our unique indicator envolves the idea that the performance analyzes carried out by the ANEEL usually involve a greater level of depth, both in accounting, regulatory and economic-financial aspects. "However, the use of a single indicator such as the one presented is not discarded, since indicators of this type have the advantage of ranking companies in a very objective way, which can be useful in the creation of more general methodologies and analyzes by ANEEL."

\section{Conclusions}

In this paper, we aim to develop a unique indicator to analyze the performance of firms in the electric sector in Brazil. We use ANEEL's indicators as a base to develop this indicator. ANEEL's indicators include five different dimensions with one or two indicators each: Indebtedness, Efficiency, Investments, Profitability, and Pay-out Ratio. Based on these dimensions and ANEEL's calculations, we create seven variables: Debt, Efficiency 1, Efficiency 2, Investments, Profitability 1, Profitability 2 and Pay-out Ratio. As an extension of Investments, we also use CapexA as a proxy for investments.

Thus, we test many different logit regressions using these seven variables as independent variables and the GPC as a dependent variable. We also create and analyze two variables as controls, dummies for Size and Public and Private, which we include as independent variables in the logit regressions (whether they interacted with other variables or not).

To develop a unique indicator, we analyze the AIC and the betas of the coefficients of the independent variables. We seek statistical significance and signs according to ANEEL's indications. After running many different logit regressions, we find an "ideal" model, which is the basis for developing a unique indicator.

Our results show that the "ideal" model for analyzing the performance of firms in the electric sector includes the 
following variables: Debt, Efficiency 1, CapexA and the Pay-out Ratio. These results show that these variables are significant for measuring firm performance for our sample. It is important to remember that in this paper, we analyze performance by using the global performance of continuity, which is an important indicator of quality, according to ANEEL.

Our results also show that CapexA is more significant than the other variables in evaluating firm performance. This result shows that investment is important for firms to show "good" performance results. Efficiency 1 is the second most important variable for firms to show "good" results. Last, debt is an important variable to evaluate firm performance, but as the beta was relatively low, it does not seem very relevant.

Finally, we conclude that it is possible to analyze firm performance of the electric sector by applying our unique indicator. Our results may be important to ANEEL and to firms in the electric sector so that they can more effectively evaluate firm performance. However, there are other aspects that do not involve only financial information. For example, future research may analyze the relation between Corporate Social Responsabilities and ANEEL indicators of electric firm performance (Sidhoum \& Serra, 2017; Ribeiro, Alves, Taffarel \& Menon (2017).

\section{Acknowledgements}

A. F., V. M., D. V., and J. Q. thank Light S.A. for supporting the research - R\&D Grant.

\section{References}

Altman, E. I. (1968). Financial ratios, discriminant analysis and the prediction of corporate bankruptcy. The Journal of Finance, 23(4), 589-609. https://doi.org/10.1111/j.1540-6261.1968.tb00843.x

ANEEL. (2016b). Nota Técnica no 111/2016-SFF/ANEEL - Instituição de indicadores públicos de sustentabilidade econômico-financeira. Brasília.

Arocena, P., \& Price, C. W. (2002). Generating efficiency: economic and environmental regulation of public and private electricity generators in Spain. International Journal of Industrial Organization, 20(1), 41-69. https://doi.org/10.1016/S0167-7187(00)00073-4

Bezerra, F. A., \& Corrar, L. J. (2006). Utilização da análise fatorial na identificação dos principais indicadores para avaliação do desempenho financeiro: uma aplicação nas empresas de seguros. Revista Contabilidade \& Finanças, 17(42), 50-62. https://doi.org/10.1590/S1519-70772006000300005

Borio, C. (2003). Towards a macroprudential framework for financial supervision and regulation? CESifo Economic Studies, 49(2), 181-215. https://doi.org/10.2139/ssrn.841306

Braga, K., Rufin, C., Brandão, R., \& Torres, E. (2016). Financial Regulation of the Electricity Distributors: Necessity and Feasibility. Energy Procedia, 106, 166-174. https://doi.org/10.1016/j.egypro.2016.12.113

Breitenbach, M., Alves, T. W., \& Diehl, C. A.(2010). Indicadores financeiros aplicados à gestão de instituições de ensino de educação básica. Contabilidade Vista \& Revista, 21(3).

Čihák, M., \& Podpiera, R. (2008). Integrated financial supervision: Which model? The North American Journal of Economics and Finance, 19(2), 135-152. https://doi.org/10.1016/j.najef.2008.03.003

Ergas, H., \& Small, J. (2001). Price caps and rate of return regulation. Network Economics Consulting Group.

Hilbers, P., Raaijmakers, K., Rijsbergen, D. R., \& De Vries, F. (2013). Measuring the effects of financial sector supervision. DNB Working Papers 388, Netherlands Central Bank, Research Department. https://doi.org/10.2139/ssrn.2321591

Huenteler, J., Dobozi, I., Balabanyan, A., \& Banerjee, S. G. (2017). Cost recovery and financial viability of the power sector in developing countries: A literature review. https://doi.org/10.1596/1813-9450-8287

Hu, B., Yin, Z., \& Zheng, L. (Eds.). (2016). Development of China's Financial Supervision and Regulation. Springer. https://doi.org/10.1057/978-1-137-52225-2

Jamasb, T., \& Pollitt, M. (2008). Security of supply and regulation of energy networks. Energy Policy, 36(12), 4584-4589. https://doi.org/10.1016/j.enpol.2008.09.007

Kishore, L., \& Varun K., S. G. (2018). Operational and financial performance optimization of power distribution utilities in India. International Journal of Pure and Applied Mathematics, 119 (15 Special Issue C), 1559-1566.

Lowry, M. N., \& Makos, M. (2020). Performance-Based Regulation: Basic Features and Possible Applications to BC Hydro. Economist. 
Meenakumari, R., \& Kamaraj, N. (2008). Measurement of relative efficiency of state-owned electric utilities in India using data envelopment analysis. Modern Applied Science, 2(5), 61-71. https://doi.org/10.5539/mas.v2n5p61

Mehdi, F., Fetz, A., \& Filippini, M. (2007). Benchmarking and regulation in the electricity distribution sector. In Servizi pubblici: nuove tendenze nella regolamentazione nella produzione e nel finanziamento, 54, 159-176. CEPE Working Paper.

Mendonça, D. J., Souza, J. A., \& Campos, R. S. (2016). Análise do desempenho dos maiores bancos brasileiros: um estudo com a análise envoltória de dados (DEA) aplicada a um conjunto de indicadores econômico-financeiros. Revista Observatório de La Economia Latino-americana, Brasil, setembro.

Pan, E. J. (2010). Challenge of international cooperation and institutional design in financial supervision: beyond transgovernmental networks. Chi. J. Int'l L., 11, 243.

Ribeiro, F., Alves, T. A., Taffarel, M., \& Menon, G. (2017). Corporate social responsibility and financial performance in the electrical energy sector: a study with panel data model. Gestão \& Regionalidade (Online), 33(99). https://doi.org/10.13037/gr.vol33n99.3987

Ringe, W. G., Morais, L. S., \& Ramos Muñoz, D. (2019). A Holistic Approach to the Institutional Architecture of Financial Supervision and Regulation in the EU. Oxford Legal Studies, 50(56). https://doi.org/10.2139/ssrn.3466649

Sidhoum, A. A., \& Serra, T. (2017). Corporate social responsibility and dimensions of performance: An application to US electric utilities. Utilities Policy, 48, 1-11. https://doi.org/10.1016/j.jup.2017.06.011

Solver, T. (2005). Reliability in performance-based regulation. (Doctoral Dissertation) Department of Electrical Systems. Royal Institute of Technology. Sweden. Retrived in https://www.diva-portal.org/smash/get/diva2:14598/FULLTEXT01.pdf

Tallapragada, V. S. N., Shkaratan, M., Izaguirre, A. K., Helleranta, J., Rahman, S., \& Bergman, S. (2009). Monitoring performance of electric utilities: indicators and benchmarking in sub-Saharan Africa. World Bank Other Operational Studies 13030, The World Bank.

Treasury, U. S. (2009). Financial Regulatory Reform: A New Foundation: Rebuilding Financial Supervision and Regulation. US White Paper on Financial Regulatory Reform.

Wymeersch, E. (2007). The structure of financial supervision in Europe: about single financial supervisors, Twin Peaks and multiple financial supervisors. European Business Organization Law Review, 8(2), 237-306. https://doi.org/10.1017/S1566752907002376

\section{Copyrights}

Copyright for this article is retained by the author(s), with first publication rights granted to the journal.

This is an open-access article distributed under the terms and conditions of the Creative Commons Attribution license (http://creativecommons.org/licenses/by/4.0/). 